\title{
Evaluation of Film Thickness of Crown Disclosing Agents and Their Comparison with Cement Film Thickness after Final Cementation
}

\author{
Muhammad Qasim Javed ${ }^{3}$ \\ ${ }^{1}$ Department of Prosthetic Dental Sciences, College of Dentistry, \\ King Saud University, Riyadh, Saudi Arabia \\ 2Department of Prosthodontics, Dental University Hospital, King \\ Saud University Medical City, Riyadh, Saudi Arabia \\ ${ }^{3}$ Department of Conservative Dental Sciences and Endodontics, \\ Qassim University College of Dentistry, Buraidah, Saudi Arabia
}

Syed Rashid Habib ${ }^{1} \quad$ Abdul Sadekh Ansari ${ }^{2} \quad$ Salwa Omar Bajunaid ${ }^{1} \quad$ Abdullah Alshahrani

\begin{abstract}
Address for correspondence Syed Rashid Habib, BDS, FCPS, Department of Prosthetic Dental Sciences, College of Dentistry, King Saud University, P. O. Box 60169, King Abdullah Road, Riyadh 11545, Saudi Arabia (e-mail: rashidhabib@hotmail.com; syhabib@ksu.edu.sa).
\end{abstract}

Eur J Dent 2020;14:224-232

\author{
Abstract \\ Keywords \\ - disclosing methods \\ - fit checker \\ - crown fit \\ - dental crowns \\ - dental crown disclos- \\ ing materials \\ - cement thickness \\ - cementation \\ - dental cement
}

Objective Verification of the accuracy of crown fit before final cementation is imperative. The aim of this in vitro study was to evaluate the film thickness of commonly used dental crown disclosing materials and their comparison with final cement thickness. Materials and Methods One hundred fifty provisional crowns (Protemp) were fabricated on standardized resin dies and divided into five groups $(N=150 ; n=30)$ based on five disclosing agents: $\mathrm{A}=$ Fit-Checker auto-mix; $\mathrm{B}=$ Okklu-top; $\mathrm{C}=$ Express; $\mathrm{D}=$ Fit-Checker hand-mix; $\mathrm{E}=$ Coltene PSI, and Final cement $=$ Relyx U200. Crowns were loaded with test materials, tried over dies under load $(50 \mathrm{~N})$, and later cemented under same load. Film thickness $(\mu \mathrm{m})$ was recorded between crown margin and the finish line of die after loading with test material and final cementation using a digital microscope.

Statistical Analysis Descriptive statistics, analysis of variance, Tukey's and paired $t$-test were used for statistical analysis $(p<0.05)$.

Results Significant variations were found between the film thicknesses of the five disclosing agents $(p=0.019)$. Group-A showed the lowest $(131.67 \pm 101.10 \mu \mathrm{m})$, while group-B $(295.00 \pm 263.88 \mu \mathrm{m})$ showed the highest film thickness $(p=0.011)$. Film thicknesses after cementation were similar for groups $(p=0.957)$. Significant difference was observed for group-B disclosing agent versus final cement $(p=0.010)$. The lowest mean difference between the film thicknesses of the disclosing agent and final cementation of $13.1 \mu \mathrm{m}$ was revealed for group-A.

Conclusions Variations in the film thicknesses of the tested disclosing agents were found. Fit-Checker auto-mix was found with minimal film thickness and satisfied the requirements as the disclosing agent, while Okklu-top aerosol spray did not.

\section{Introduction}

An optimal indirect dental restoration involves several clinical and laboratory steps. ${ }^{1}$ The final clinical procedure of cementation is very critical and any major error during this step may ruin the hard word put in the clinical and laboratory steps. ${ }^{2,3}$ However, the minor errors such as in the form of marginal discrepancy may promote the progression of secondary caries and compromise the long-term prognosis of the abutment tooth. ${ }^{4,5}$ The marginal fit of an indirect restoration
DOI https://doi.org/

$10.1055 / \mathrm{s}-0040-1708560$

ISSN 1305-7456.
License terms

(요 (1) $\odot \circledast$ 
to the finish line is considered optimal if the gap between the two is up to 25 microns $(\mu \mathrm{m}){ }^{6}$ The marginal discrepancy of up to $200 \mu \mathrm{m}$ is considered to be clinically undetectable. ${ }^{7}$ Though this may be considered clinically acceptable, this gap is large enough for harboring the microorganisms from the oral microflora and increasing the chances of irreversible destruction of the abutment tooth structure. ${ }^{8}$ Thus, the importance of optimal cementation of indirect restorations cannot be overemphasized.

Assessment of the marginal and internal fit of the indirect restoration before its final cementation clinically is a challenging task. The naked eye or the tactile method using a sharp explorer can detect a marginal discrepancy of more than $200 \mu \mathrm{m},{ }^{9}$ anything less than that is undetectable with the visual inspection or tactical sensations. According to Björn et al, ${ }^{9}$ marginal defects of $300 \mu \mathrm{m}$ were clinically undetectable in all ceramic crowns that were evaluated radiographically. In another study by Christensen, ${ }^{10}$ it was reported that even experienced restorative dentists cannot detect the marginal discrepancies as great as $119 \mu \mathrm{m}$. In addition, the detection of any marginal discrepancy on the proximal surfaces, subgingival surfaces, and the internal gap discrepancy cannot be accomplished by visual inspection only.

Various methods and materials have been adapted and used for the verification of the marginal and internal fit of the indirect restorations before their final cementation to the abutment teeth. Close inspection of the margins and fitting surface of the restorations is recommended in the contemporary textbooks. ${ }^{4,5}$ True evaluations can be accomplished by using recommended disclosing agents or fit checking materials like disclosing wax, rouge with nonhazardous solvent, aerosol sprays, elastomeric impression materials of low viscosity, and silicone-based disclosing agents. These materials not only help in disclosing the interference areas but also help in revealing the marginal discrepancies and verification of the internal cement film thickness provided in the form of die spacer.

To avoid the wrong details about the marginal and internal fit of the indirect restoration, the film thickness of disclosing materials must have an equal or less than the film thickness set forth by ISO standard for the final cementation that is $25 \mu \mathrm{m}$ for water-based cements and $50 \mu \mathrm{m}$ for resin cements. ${ }^{11,12}$ The final cementation is also greatly influenced by the pressure applied occlusally during the cementation procedure. The force applied by the dentist depends on the finger pressure and varies between the different dentists. The standardization of the pressure applied during cementation is still subjective even if it's done by the same dentist. Some studies have shown that the increase in the seating forces applied during the cementation may reduce the marginal discrepancies of up to more than $50 \% .^{13}$ Thus, it underscores the importance and relevance of optimal and standardized seating force application prior to the final cementation with disclosing agents as well as during the final cementation of the indirect restorations.

Many research studies have attempted to evaluate the various factors involved in the marginal discrepancies of the dental crowns and also evaluated the film thickness of the disclosing materials. However, the evaluation of film thickness of the disclosing materials, together with the evaluation of the final cement thickness under standardized loading and their comparison, is missing. Thus, the aim of this in vitro research was to evaluate the film thickness of various dental crown disclosing materials and their comparison with cement thickness of the final cement, after the final cementation of the dental crowns under standardized seating load. The null hypothesis was that all the disclosing materials will have similar film thickness comparable to the final cement thickness.

\section{Materials and Methods}

Before initiation of the study, ethical clearance was obtained from the ethics committee at the College of Dentistry Research Center (CDRC), King Saud University (Registration no. FR 0515). The study was conducted from October 2019 to December 2019 at the Department of Prosthodontics and CDRC, College of Dentistry, King Saud University, Riyadh, KSA.

For this research study, the test materials included five commonly used dental crown disclosing agents and a self-adhesive resin cement ( - Table $\mathbf{1}$ ). One hundred

Table 1 Details of the tested disclosing agents and final cement used in the research study

\begin{tabular}{|l|l|l|l|l|l|}
\hline S. No. & Group & Material & Trade name & Manufacturer & Lot number \\
\hline 1. & Group-A & $\begin{array}{l}\text { Addition silicone auto-mix } \\
\text { disclosing agent }\end{array}$ & $\begin{array}{l}\text { Fit Checker Advanced } \\
\text { Blue }\end{array}$ & GC Corporation; Tokyo, Japan & 1808021 \\
\hline 2. & Group-B & Aerosol spray & Hanel Okklu-top & $\begin{array}{l}\text { Coltene/Whaledent GmbH, } \\
\text { Germany }\end{array}$ & A2225 \\
\hline 3. & Group-C & $\begin{array}{l}\text { Vinyl Polysiloxane light } \\
\text { body impression }\end{array}$ & 3M ESPE Express & 3M ESPE; MN 55144, USA & N904221 \\
\hline 4. & Group-D & $\begin{array}{l}\text { Addition silicone hand-mix } \\
\text { disclosing agent }\end{array}$ & Fit Checker Advanced & GC Corporation; Tokyo, Japan & $23 B 2 X 00038000038$ \\
\hline 5. & Group-E & $\begin{array}{l}\text { Condensation silicone } \\
\text { hand-mix disclosing agent }\end{array}$ & Coltene PSI & $\begin{array}{l}\text { Coltene/Whaledent AG, } \\
\text { Switzerland }\end{array}$ & L81743 \\
\hline 6. & $\begin{array}{l}\text { Final } \\
\text { cementation }\end{array}$ & $\begin{array}{l}\text { Self-adhesive resin cement } \\
\text { Relyx U200 Automix }\end{array}$ & $\begin{array}{l}\text { 3M ESPE; 3M Deutschland } \\
\text { GmbH, 41453 Neuss, } \\
\text { Germany }\end{array}$ & 5100524 \\
\hline
\end{tabular}


and fifty $(N=150)$ provisional crowns (Protemp Plus; 3M ESPE, Germany) were fabricated on duplicated resin dies of prepared ivorine tooth and randomly divided into five groups ( $n=30$ ) based on the five types of disclosing agents. The details of all the tested materials is presented in - Table $\mathbf{1}$.

\section{Master Die Preparation and Fabrication of Indexes}

To fabricate the standardized master die of a prepared tooth, an ivorine mandibular right first molar no. 46 (KaVo Dental GmbH, Germany) was mounted on acrylic resin base (Ortho-Resin; DeguDent GmbH, Germany) of $2 \times 2 \mathrm{~cm}$ size, exposing the anatomic crown and $2 \mathrm{~mm}$ of the coronal root surface. A total of 150 indexes (Virtual Putty; Ivoclar, Vivadent Inc., United States) were fabricated over the unprepared tooth. The mounted tooth was then prepared for an allceramic crown, with recommended guidelines (-Fig. 1). ${ }^{14,15}$

\section{Duplicated Master Dies Fabrication}

One hundred fifty final impressions (polyvinyl siloxane [PVS], Virtual XD 380, Ivoclar, Vivadent Inc., United States) were recorded for the prepared master die in customized impression trays. Impressions with any defects on visual inspection were discarded. The selected impressions were poured with resin (Ortho-Resin, DeguDent GmbH, Germany) for the fabrication of the duplicated master dies (-Fig. 2). Samples with any distortions or defects were discarded and the impressions re poured.

\section{Provisional Crowns Fabrication}

The duplicated resin dies were painted with two layers of die spacer (Yeti; Yeti GmbH, Germany) on entire axial and occlusal surface except 0.5 to $1 \mathrm{~mm}$ of finish line. Silicone Putty Indexes fabricated earlier over the unprepared master tooth were loaded with provisional crown material (Protemp Plus; 3M ESPE, Germany) using auto mixing gun and seated over the duplicated resin dies. Manufacturer's instructions were followed and after the complete setting the provisional crowns were removed from their respective dies ( - Fig. $\mathbf{3}$ ). The intaglio surface of crown margin marked with a lead pencil and the provisional crowns were finished with acrylic

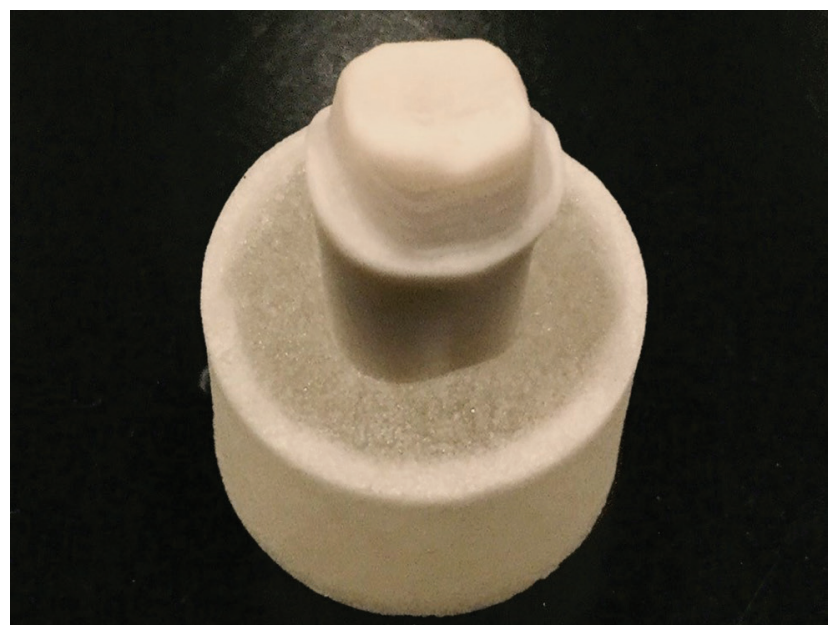

Fig. 1 Prepared ivorine tooth (master die).

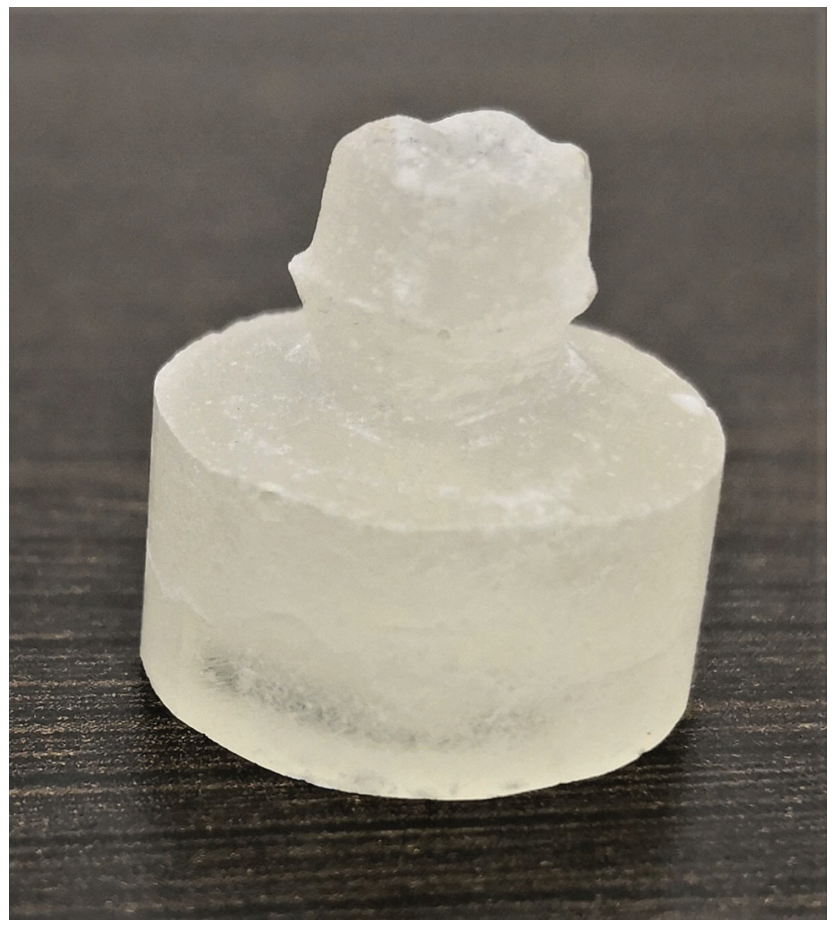

Fig. 2 Duplicated resin die of the master die.

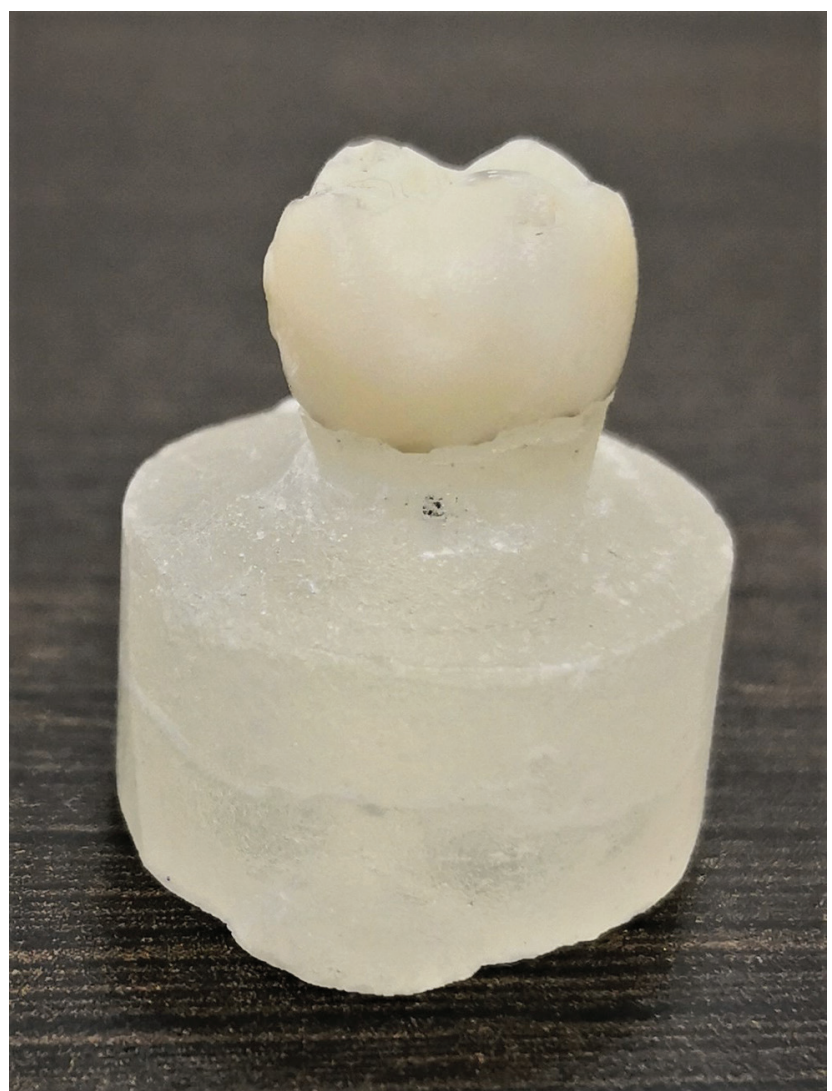

Fig. 3 Sample of fabricated provisional crown over the duplicated resin die.

burs (H79E040; All-purpose E-Cutter system, Dental Instrumentation, Brasseler, United States) using a low speed straight hand piece (KaVo Dental; GmbH, Biberach, Germany). Provisional crowns found with defects visually were discarded 
and remade. All the 150 fabricated samples were then stored in distilled water at room temperature for 24 hours.

\section{Application of Disclosing Agents and Final Cementation} For groups-A and $-\mathrm{C}$, the materials were dispensed in the intaglio surface of the crowns with the help of auto mixing/dispensing guns as per manufacturers' instructions. For the group-B samples, the bottle was shaked and material was sprayed onto the intaglio surface of crowns for $2 \mathrm{sec}-$ onds to create a uniform layer of the disclosing material as per manufacturer's instructions. For the samples in group-D and $-E$, the materials were hand-mixed in equal proportions until uniform color was obtained, followed by loading the crowns with the help of a plastic instrument. After application of the disclosing materials, all the specimen crowns were placed onto their respective dies under a standardized vertical load of $5 \mathrm{~kg}(50 \mathrm{~N})$. The load was applied on the occlusal surface with the help of a customized dental Surveyor ( - Fig. 4) until each material setting time was completed, followed by the excess flash trimming with sharp blade. ${ }^{13}$

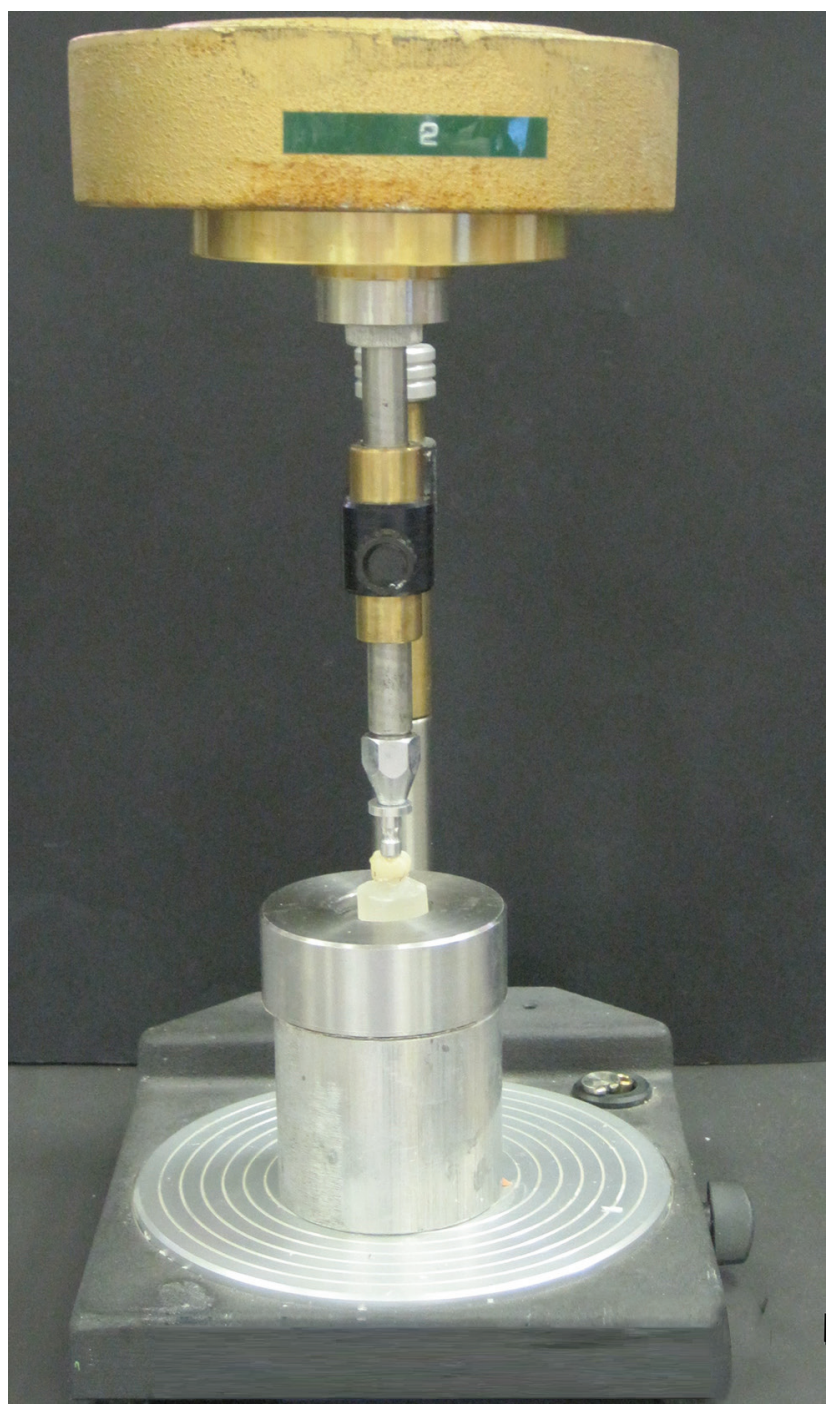

Fig. 4 Customized dental surveyor for standardized loading.
After the measurements, all the crowns were hand/ultrasonic cleaned, dried, and cemented with resin cement (Relyx U200 Automix; 3M ESPE, 3M Deutschland GmbH, 41453 Neuss, Germany). Automixing gun was used for dispensing the cement in equal amounts and cementation completed under the similar conditions used for the disclosing agents.

\section{Microscopic Film Thickness Measurement}

To determine the film thickness of five disclosing agents and the resin cement, vertical distance was measured using built-in software of a digital microscope (Digital Microscope, KH-7700; Hirox-USA, Inc., New Jersey, United States) at each of the four axial line angles (mesiobuccal, distobuccal, distolingual, and mesiolingual). All the specimens were stabilized on the microscope table with customized locking device ( - Fig. 5) and measurements recorded from the external crown margin to a perpendicular corresponding point on the finish line of the resin die with the help of a micrometer ruler placed in the field of view to calibrate the computer software program. The measurements were recorded before and after application of disclosing agents and after final cementation with resin cement ( - Fig. 6). All the measurements were recorded by one trained digital microscope technician.

\section{Calculation of Mean Film Thickness for Each Tested Material}

To obtain the film thickness of all the tested disclosing agents and the final cement material for each sample, the mean of all four digital microscopic measurements recorded for each sample was calculated before and after application of fit checking materials and after final cementation. The film thickness was calculated by subtracting the measurements obtained before (Pre) disclosing material/cement application from the measurements obtained after (Post) disclosing materials and final cement application.

\section{Statistical Analysis}

The obtained data was statistically analyzed by entering in SPSS version 22 (SPSS Inc.; Chicago, Illinois, United States). One-way analysis of variance (ANOVA) test was performed to determine whether there was a significant difference between the film thickness of five test group disclosing materials and film thickness of final cement. Multiple comparisons between the film thicknesses of materials were performed using post-hoc Tukey's tests. Paired $t$-test was applied to evaluate the statistical difference between film thickness of each group disclosing material and final cement. The probability for statistical significance was set at $\alpha<0.05$ (-Tables 2-4).

\section{Results}

The current in vitro study evaluated the film thickness of dental crown disclosing agents and compared their film thickness with cement thickness after final cementation of the crowns. Three measurements (pre-disclosing agent application/cementation; post-disclosing agent application; 


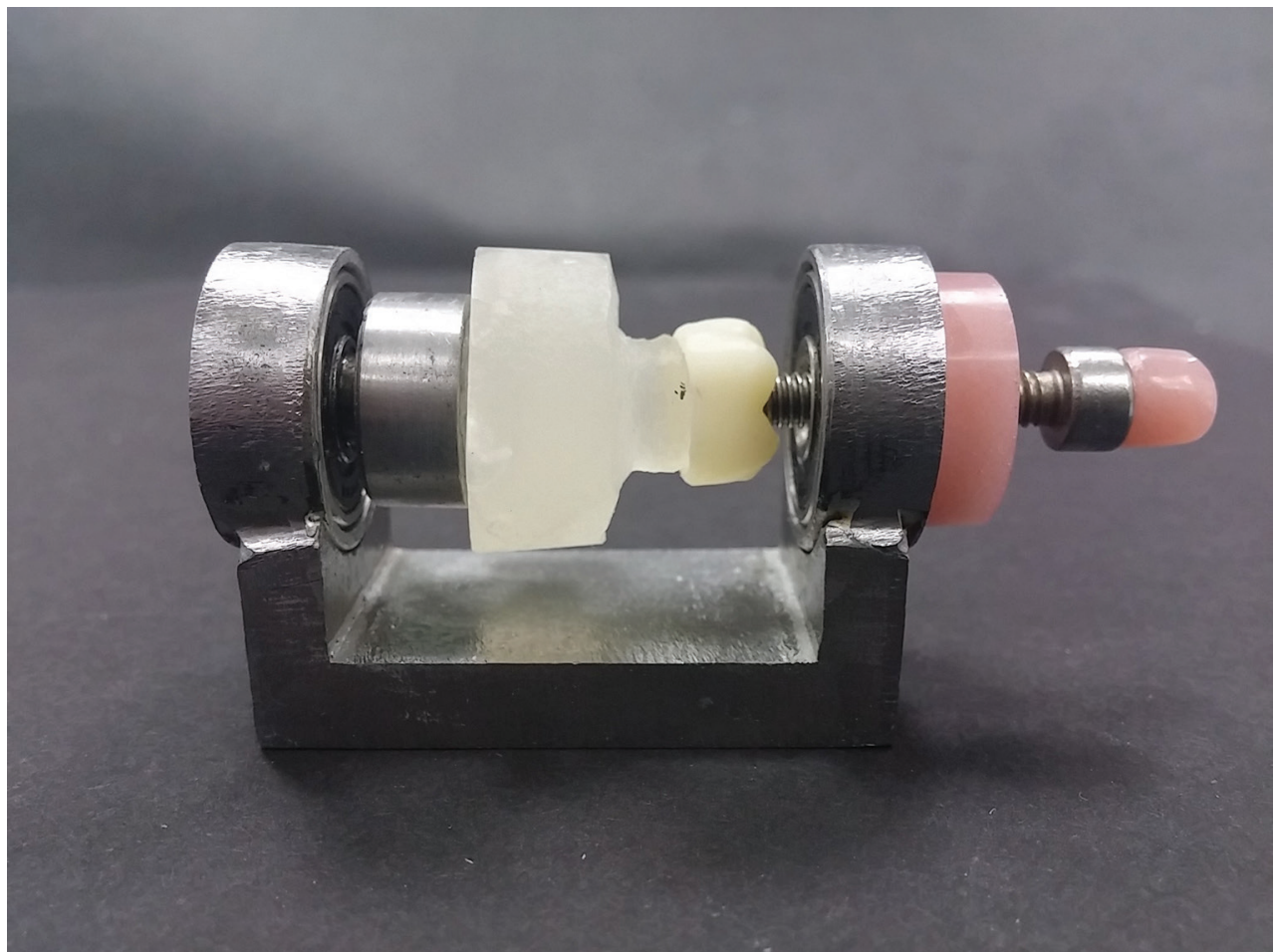

Fig. 5 Customized locking device for stabilization of the provisional crown over the die during the microscopic measurement.

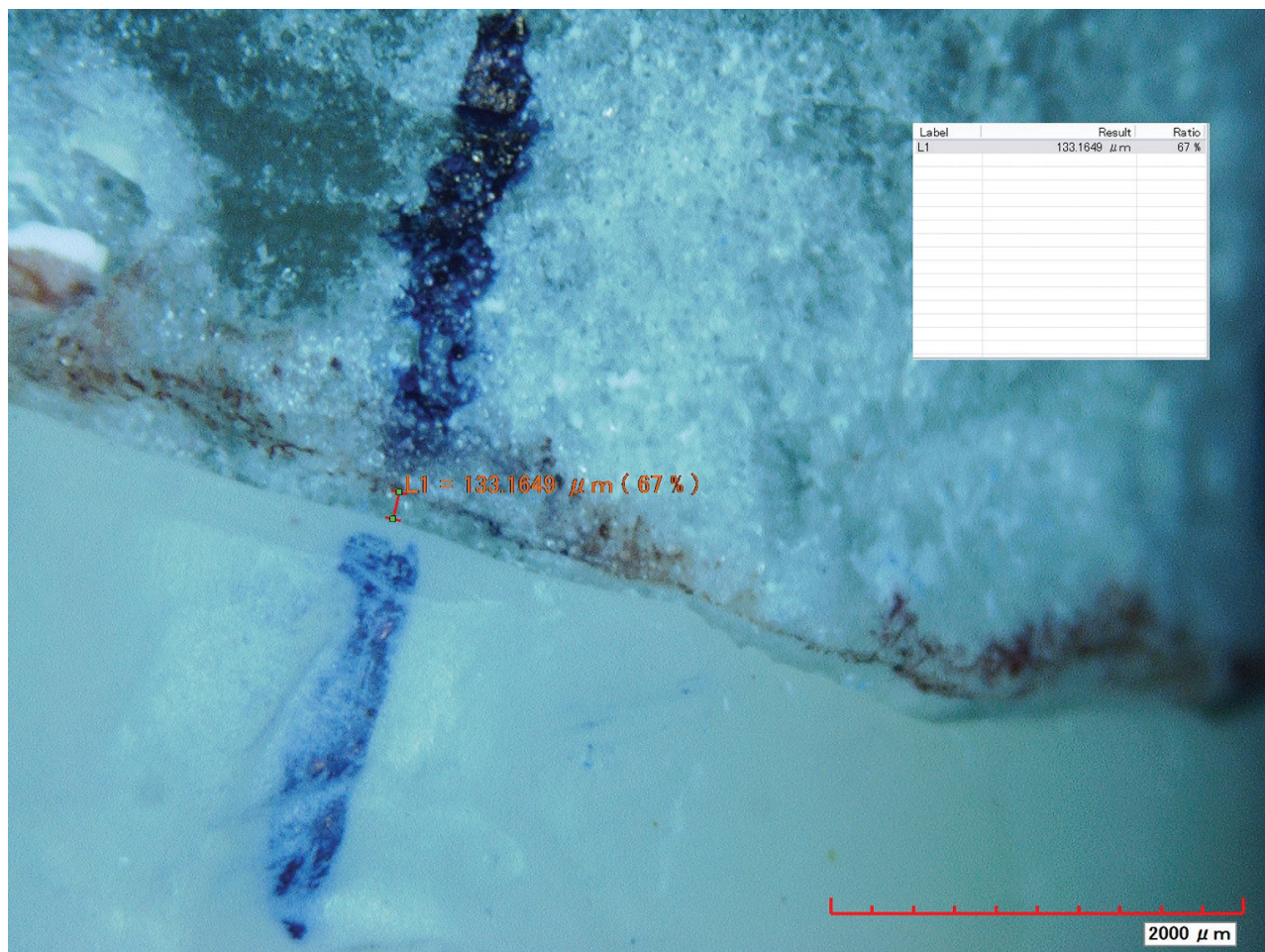

Fig. 6 Measurement with the digital microscopic ruler in micrometers.

post-cementation) were recorded for all the specimens of the five groups of materials.

- Table 2 presents the descriptive statistics for the film thicknesses in micrometers $(\mu \mathrm{m})$ of all the disclosing agents and film thickness of the final cementation material. Significant variation was found between the film thicknesses of the five groups of disclosing agents as one-way ANOVA confirmed statistically significant difference $(p=0.019)$. The lowest film thickness was observed for the group- $\mathrm{A}(131.67 \pm 101.10 \mu \mathrm{m})$ while the highest for group-B $(295.00 \pm 263.88 \mu \mathrm{m})$. Similarities between the film thicknesses were observed for the final cement of the five post-cementation groups. This was 
Table 2 Descriptive statistics with mean, standard deviation, and ANOVA results of film thicknesses for all the tested disclosing materials and final cementation $(N=150)$

\begin{tabular}{|c|c|c|c|c|c|c|c|c|c|}
\hline & \multirow[t]{2}{*}{ Material groups } & \multirow[t]{2}{*}{$N$} & \multirow[t]{2}{*}{ aMean } & \multirow[t]{2}{*}{ SD } & \multicolumn{2}{|c|}{$\begin{array}{l}95 \% \text { Confidence interval } \\
\text { for mean }\end{array}$} & \multirow[t]{2}{*}{ Minimum } & \multirow[t]{2}{*}{ Maximum } & \multirow[t]{2}{*}{ ANOVA $p$-value } \\
\hline & & & & & Lower bound & $\begin{array}{l}\text { Upper } \\
\text { bound }\end{array}$ & & & \\
\hline \multirow{6}{*}{ 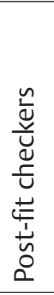 } & Group-A & 30 & 131.67 & 101.10 & 93.91 & 169.41 & 0.00 & 350.00 & \multirow[t]{6}{*}{0.019} \\
\hline & Group-B & 30 & 295.00 & 263.88 & 196.46 & 393.53 & 30.00 & 1140.00 & \\
\hline & Group-C & 30 & 216.33 & 214.83 & 136.11 & 296.55 & 30.00 & 920.00 & \\
\hline & Group-D & 30 & 244.33 & 186.83 & 174.56 & 314.09 & 20.00 & 720.00 & \\
\hline & Group-E & 30 & 185.33 & 156.99 & 126.71 & 243.95 & 10.00 & 620.00 & \\
\hline & Total & 150 & 214.53 & 197.87 & 182.60 & 246.45 & 0.00 & 1140.00 & \\
\hline \multirow{6}{*}{ 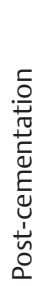 } & Group-A & 30 & 152.00 & 179.27 & 85.05 & 218.94 & 0.00 & 760.00 & \multirow[t]{6}{*}{0.957} \\
\hline & Group-B & 30 & 156.33 & 133.17 & 106.60 & 206.06 & -50.00 & 420.00 & \\
\hline & Group-C & 30 & 165.00 & 96.48 & 128.97 & 201.02 & 0.00 & 440.00 & \\
\hline & Group-D & 30 & 172.00 & 92.07 & 137.61 & 206.38 & 10.00 & 350.00 & \\
\hline & Group-E & 30 & 172.33 & 99.98 & 134.99 & 209.66 & 30.00 & 380.00 & \\
\hline & Total & 150 & 163.53 & 123.21 & 143.65 & 183.41 & -50.00 & 760.00 & \\
\hline
\end{tabular}

Abbreviations: ANOVA, analysis of variance; SD, standard deviation.

aMean film thickness was measured in micrometers $(\mu \mathrm{m})$.

further confirmed with ANOVA as no statistically significant difference $(p=0.957)$ was found ( - Table 2 ).

The mean differences between the film thicknesses of the tested disclosing agents and their one to one comparison with post-hoc Tukey's test are presented in - Table 3. The highest mean difference of $163.33 \mu \mathrm{m}$ was observed between group-A and group-B, which was found to be statistically significant $(p=0.011)$. No significant differences were found between rest of the group materials ( - Table 3 ).

Paired samples $t$-test was used for the comparison between the film thicknesses of the disclosing agents and film thickness of the cement after the final cementation of the same group specimens. The pair number 2 (Hanel Okklu-top vs. Relyx U200 Resin cement) showed the highest mean difference of $138.67 \mu \mathrm{m}$ that was statistically significant $(p=0.010)$ ( - Table 4$)$. The mean differences between the film thicknesses of the disclosing agents and final cementation of 13.1 and $20.33 \mu \mathrm{m}$ were revealed for group-A and group-E, respectively ( - Table 4). Among the materials tested the film thickness for the group-A disclosing agent was found to be the nearest to the film thicknesses of the final cement in the same group.

\section{Discussion}

In this in vitro research study, the film thicknesses of five different crown disclosing agents/materials were evaluated and compared with the film thickness of final cementation material. Ideally crown disclosing materials should verify crown's marginal and internal adaptation precisely and also should identify interferences that prevent complete seating of the crowns on the prepared teeth. ${ }^{16,17}$ To prevent the false information about the fit of crowns during seating and try-in, these fit checking materials should have the film thickness similar or less than that of the final cementation material..$^{18,19}$ Various studies have been performed on the film thickness of different crown disclosing agents, but data regarding their comparison with film thickness of final cement material is lacking. ${ }^{13,16-22}$ Besides, some research studies evaluated the film thickness of disclosing agents between two similar flat surfaces. ${ }^{18}$ This is in contrast to the actual clinical scenario where the shape of intaglio surface of a crown and the prepared abutment tooth are completely different from each other. The flow dynamics and behavior of the disclosing material or cement in between these two surfaces will be different than between two flat surfaces. This current study attempted to simulate clinical scenario under standardized occlusal load for the evaluation of the film thickness of disclosing agents as well as the final cement thickness.

For this study, duplicated resin dies of the ideally prepared tooth were prepared and individualized provisional crowns were fabricated over each resin die to be used as specimens. This method, which has previously been used by some researchers ${ }^{2,23}$ successfully, was employed to standardize the specimen fabrication for all the test groups. Digital microscope was used for the evaluation of the film thickness before and after the application of the disclosing agents and the final cement. Use of digital microscope in the evaluation of the marginal discrepancies is well documented ${ }^{2,23-25}$ and not new. The film thickness of the disclosing agents and the final cement was measured between the crown margin of the provisional and the finish line of the abutment tooth at the four-line angles between the axial walls. Alabdulkader and Habib, ${ }^{2}$ Al Rifaiy, ${ }^{23}$ and Habib ${ }^{24}$ have used the similar technique/methodology and found it appropriate for the measurement of the marginal discrepancies/cement thickness. The authors found this methodology to be useful keeping in view the objective of the current research that was to 
Table 3 Multiple comparisons and mean differences of the film thicknesses among the groups by post-hoc Tukey's HSD test

\begin{tabular}{|c|c|c|c|c|}
\hline Dependent variable & Groups & Groups & Mean difference & Significant ${ }^{\mathrm{a}}$ \\
\hline \multirow[t]{20}{*}{ Post fit checkers } & \multirow[t]{4}{*}{ Group-A } & Group-B & $-163.33^{a}$ & 0.011 \\
\hline & & Group-C & -84.66 & 0.436 \\
\hline & & Group-D & -112.66 & 0.162 \\
\hline & & Group-E & -53.66 & 0.817 \\
\hline & \multirow[t]{4}{*}{ Group-B } & Group-A & $163.33^{\mathrm{a}}$ & 0.011 \\
\hline & & Group-C & 78.66 & 0.512 \\
\hline & & Group-D & 50.66 & 0.846 \\
\hline & & Group-E & 109.66 & 0.184 \\
\hline & \multirow[t]{4}{*}{ Group-C } & Group-A & 84.66 & 0.436 \\
\hline & & Group-B & -78.66 & 0.512 \\
\hline & & Group-D & -28.00 & 0.980 \\
\hline & & Group-E & 31.00 & 0.971 \\
\hline & \multirow[t]{4}{*}{ Group-D } & Group-A & 112.66 & 0.162 \\
\hline & & Group-B & -50.66 & 0.846 \\
\hline & & Group-C & 28.00 & 0.980 \\
\hline & & Group-E & 59.00 & 0.759 \\
\hline & \multirow[t]{4}{*}{ Group-E } & Group-A & 53.66 & 0.817 \\
\hline & & Group-B & -109.66 & 0.184 \\
\hline & & Group-C & -31.00 & 0.971 \\
\hline & & Group-D & -59.00 & 0.759 \\
\hline
\end{tabular}

Abbreviation: HSD, honestly significant difference.

aThe mean difference is significant at the $p \leq 0.05$ level.

Table 4 Pair wise comparison of film thicknesses of each disclosing agent with final cement of the same group by paired samples t-test

\begin{tabular}{|c|c|c|c|c|c|c|}
\hline & Materials tested & Mean & $N$ & SD & SE mean & $p$-Value ${ }^{a}$ \\
\hline \multirow{2}{*}{$\begin{array}{l}\text { Pair } 1 \\
\text { Group-A }\end{array}$} & Fit Checker Advanced Blue & 131.67 & 30 & 101.10 & 18.45 & \multirow[t]{2}{*}{0.541} \\
\hline & Relyx U200 Resin cement & 152.00 & 30 & 179.27 & 32.73 & \\
\hline \multirow{2}{*}{$\begin{array}{l}\text { Pair } 2 \\
\text { Group-B }\end{array}$} & Hanel Okklu-top & 295.00 & 30 & 263.88 & 48.17 & \multirow[t]{2}{*}{0.010} \\
\hline & Relyx U200 Resin cement & 156.33 & 30 & 133.17 & 24.31 & \\
\hline \multirow[t]{2}{*}{$\begin{array}{l}\text { Pair } 3 \\
\text { Group-C }\end{array}$} & $\begin{array}{l}\text { Express Vinyl Polysiloxane light body } \\
\text { impression }\end{array}$ & 216.33 & 30 & 214.83 & 39.22 & \multirow[t]{2}{*}{0.185} \\
\hline & Relyx U200 Resin cement & 165.00 & 30 & 96.48 & 17.61 & \\
\hline \multirow{2}{*}{$\begin{array}{l}\text { Pair } 4 \\
\text { Group-D }\end{array}$} & Fit Checker Advanced & 244.33 & 30 & 186.83 & 34.11 & \multirow[t]{2}{*}{0.050} \\
\hline & Relyx U200 Resin cement & 172.00 & 30 & 92.07 & 16.81 & \\
\hline \multirow{2}{*}{$\begin{array}{l}\text { Pair } 5 \\
\text { Group-E }\end{array}$} & Coltene PSI & 185.33 & 30 & 156.99 & 28.66 & \multirow[t]{2}{*}{0.653} \\
\hline & Relyx U200 Resin cement & 172.33 & 30 & 99.98 & 18.25 & \\
\hline
\end{tabular}

Abbreviations: SD, standard deviation; SE, standard error.

aThe comparison is significant at the $p \leq 0.05$ level.

measure the film thickness of the disclosing agents and final cement under standardized and simulated clinical scenario.

Among the various disclosing agents available for the checking of the indirect restorations, silicone-based materials are the most commonly used. ${ }^{18,21,26}$ Three-dimensional evaluation of the interferences evident in different thicknesses, availability in different colors for accurate detection of the interferences with contrast, operator friendly hand-mixing and auto-mixing options, excellent tear resistance, and ease of removability without leaving any remnants/residues on the fitting surface of the restorations are advantages of using silicone-based disclosing agents. ${ }^{16}$ Use of the auto-mixing addition silicones is also recommended by Jahangiri and Estafan, ${ }^{27}$ and Keys ${ }^{28}$ who found its thickness to be appropriate for finding interferences and similar to the final cement thickness. The results of the current study confirmed this as the only material with film thickness less than the final cement for group-A that was auto-mixed silicone-based 
disclosing material. This indicates that group-A (Fit Checker Advanced Blue Automix) can detect crown misfit as accurately as possible.

In terms of film thickness the next disclosing material, close to the final cement thickness was found to be the group-E (Coltene PSI, condensation silicone hand-mix disclosing agent). The comparison between the addition silicones or condensation silicones based disclosing agents is not documented in literature. Though, the accuracy of condensation silicones as impression materials is comparable to addition silicones but with minor inaccuracies for condensation silicones. ${ }^{29,30}$ These minor dimensional changes due to the difference in the chemical composition of the two materials could possibly be the reason for the slight nonsignificant difference between the group-A and group-E materials tested in the current study.

Attainment of a uniform layer of the aerosol spray type disclosing agents on the fitting surface of crowns is found to be difficult as reported by Kious et al..$^{18}$ The sprayed material dispenses various film thicknesses at different spraying time and distance. ${ }^{21}$ This observation was evident in the present study as the group-B (aerosol spray) showed the maximum film thickness $(295 \mu \mathrm{m})$ with highest standard deviation $(263.88 \mu \mathrm{m})$ among the tested materials. The results showed some significant variations between the film thicknesses recorded for the group-B specimens with as low as $30 \mu \mathrm{m}$ and as high as $1140 \mu \mathrm{m}$. This finding further corroborates the variations associated with aerosol spray type disclosing agents. Furthermore, the colored remnants become a botheration as it is difficult to remove all the residues completely/ cleanly, the material is sensitive, and can be displaced easily by moisture and can be inadvertently wiped off if restoration is not fitted or removed along the path of withdrawal, thus disclosing a false interference. ${ }^{18,21}$ Due to the variations in the film thicknesses and above-mentioned reasons, the aerosol spray may not detect interferences accurately. ${ }^{18}$

Due to easy availability of PVS impression materials, ${ }^{31}$ it was tested for usage as a disclosing agent in this study. Though the film thickness of the PVS was high as compared with the auto-mix fit checker, it was found to be less than the handmixed fit checker. The observation based on the results of the current study recommends PVS to be used for the detection of the interferences associated with the fitting surface of crowns, in case of unavailability of the disclosing materials.

Some possible limitations of the study included dimensional inaccuracies in the resin dies due to inherent property of autopolymerising resin setting reaction, marginal and internal discrepancies due to shrinkage of the provisional crown material, manual application of the die spacer, and digital microscopic measurements. The possibility of errors in the dies and provisional crowns was minimized by fabrication of individualized crowns over each resin die. Considering the mean of four measurements recorded for each sample as the final film thickness of each tested specimen was planned to eliminate the errors associated with microscopic measurements.

\section{Conclusions}

In conclusion, variations in the film thicknesses of the tested disclosing agents were found. The similarity in film thickness of the Fit Checker Advanced Blue Auto-mix to the final cement film thickness makes it the choice of material as a disclosing agent for accurate detection of the interferences associated with intaglio surfaces of dental crowns. Due to significant variations associated with aerosol spray disclosing agents, in clinical situations achieving a uniform thickness on the intaglio surface of a crown would likely be less predictable.

\section{Funding}

This research project was approved by the College of Dentistry Research Center (Registration no. IR 0515) and Deanship of Scientific Research at King Saud University.

\section{Conflict of Interest}

None declared.

\section{References}

1 Opdam N, Frankenberger R, Magne P. From 'direct versus indirect' toward an integrated restorative concept in the posterior dentition. Oper Dent 2016;41(S7) :S27-S34

2 Alabdulkader MA, Habib SR. Effect of cement application techniques on the adaptation and retention of provisional crowns. Technol Health Care 2018;26(6):945-955

3 Wilson PR. Crown behaviour during cementation. J Dent 1992;20(3):156-162 Review

4 Johnson GH, Lepe X, Patterson A, Schäfer O. Simplified cementation of lithium disilicate crowns: retention with various adhesive resin cement combinations. J Prosthet Dent 2018;119(5):826-832

5 Krämer N, Möhwald M, Lücker S, et al. Effect of microparticulate silver addition in dental adhesives on secondary caries in vitro. Clin Oral Investig 2015;19(7):1673-1681

6 Bagheri R. Film thickness and flow properties of resin-based cements at different temperatures. J Dent (Shiraz) 2013;14(2):57-63

7 Ladha K, Verma M. Conventional and contemporary luting cements: an overview. J Indian Prosthodont Soc 2010; 10(2):79-88

8 Habib SR, Ali M, Al Hossan A, Majeed-Saidan A, Al Qahtani M. Effect of cementation, cement type and vent holes on fit of zirconia copings. Saudi Dent J 2019;31(1):45-51

9 Björn AL, Björn H, Grkovic B. Marginal fit of restorations and its relation to periodontal bone level. II. Crowns. Odontol Revy 1970;21(3):337-346

10 Christensen GJ. Marginal fit of gold inlay castings. J Prosthet Dent 1966;16(2):297-305

11 International Organization for Standardization. ISO 9917-1:2007. Dentistry-water based cements-part 1: powder/liquid acid-base cements. Available at: http:// www.iso.ch/iso/en/prods-services/ ISOstore/store.html. Accessed November 30, 2019

12 International Organization for Standardization. ISO No. 4049:2000. Dentistry-polymer-based filling, restorative and luting materials. Geneva: ISO. Available at: http:// www.iso.ch/ iso/en/prods-services/ISOstore/store.html. Accessed November 30, 2019

13 Zortuk M, Bolpaca P, Kilic K, Ozdemir E, Aguloglu S. Effects of finger pressure applied by dentists during cementation of all-ceramic crowns. Eur J Dent 2010;4(4):383-388 
14 Shillingburg HT Jr, Hobo S, Whitsett LD, et al. Principles of tooth preparations. In Shillingburg HT Jr, Hobo S, Whitsett LD, et al, eds. Fundamentals of Fixed Prosthodontics. 3rd ed. Chicago: Quintessence; 1997 119-154

15 Rosenstiel S, Land M, Fujimoto J, Contemporary Fixed Prosthodontics. St Louis: Mosby Elsevier; 2006

16 Check the fit accuracy of prosthetics. Br Dent J 2014;216:204, 10.1038/sj.bdj.2014.139

17 Mirfazaelian A. Fabricating a fit checker. J Prosthet Dent 2000;83(3):376

18 Kious AR, Roberts HW, Bracket WW. Film thickness of recently introduced luting cements. J Prosthet Dent 1992;68:476-481

19 White SN, Yu Z. Film thickness of new adhesive luting agents. J Prosthet Dent 1992;67(6):782-785

20 Ushiwata O, de Moraes JV, Bottino MA, da Silva EG. Marginal fit of nickel-chromium copings before and after internal adjustments with duplicated stone dies and disclosing agent. J Prosthet Dent 2000;83(6):634-643

21 Troendle GR, Troendle KB, Cavazos E Jr. Film thickness of four disclosing media. J Prosthet Dent 1991;65(6):856-857

22 White SN, Sorensen JA, Kang SK. Improved marginal seating of cast restorations using a silicone disclosing medium. Int J Prosthodont 1991;4(4):323-326

23 Al Rifaiy MQ. Evaluation of vertical marginal adaptation of provisional crowns by digital microscope. Niger J Clin Pract 2017;20(12):1610-1617
24 Habib SR. Digital microscopic evaluation of vertical marginal discrepancies of CAD/CAM fabricated zirconia cores. Biomed Tech (Berl) 2019;64(2):207-214

25 Özçelik TB, Yilmaz B, Şeker E, Shah K. Marginal adaptation of provisional $\mathrm{CAD} / \mathrm{CAM}$ restorations fabricated using various simulated digital cement space settings. Int J Oral Maxillofac Implants 2018;33(5):1064-1069

26 Pohjola RM. FIT CHECKER for all ceramic restorations. Oper Dent 2004;29(3):346

27 Jahangiri L, Estafan D. A method of verifying and improving internal fit of all-ceramic restorations. J Prosthet Dent 2006;95(1):82-83

28 Keys LG. An alternate method of verifying the seating of allceramic restorations. J Prosthet Dent 2002;87(4):411

29 Kamble SS, Khandeparker RV, Somasundaram P, Raghav S, Babaji RP, Varghese TJ. Comparative evaluation of dimensional accuracy of elastomeric impression materials when treated with autoclave, microwave, and chemical disinfection. J Int Oral Health 2015;7(9):22-24

30 Joshi P, Bhat GS, Shenoy V. Comparative evaluation of dimensional accuracy of addition silicone and condensation silicone impression materials - an invitro study. J Nepal Dent Assoc 2009;10:88-96

31 Rubel BS. Impression materials: a comparative review of impression materials most commonly used in restorative dentistry. Dent Clin North Am 2007;51(3):629-642, vi 